
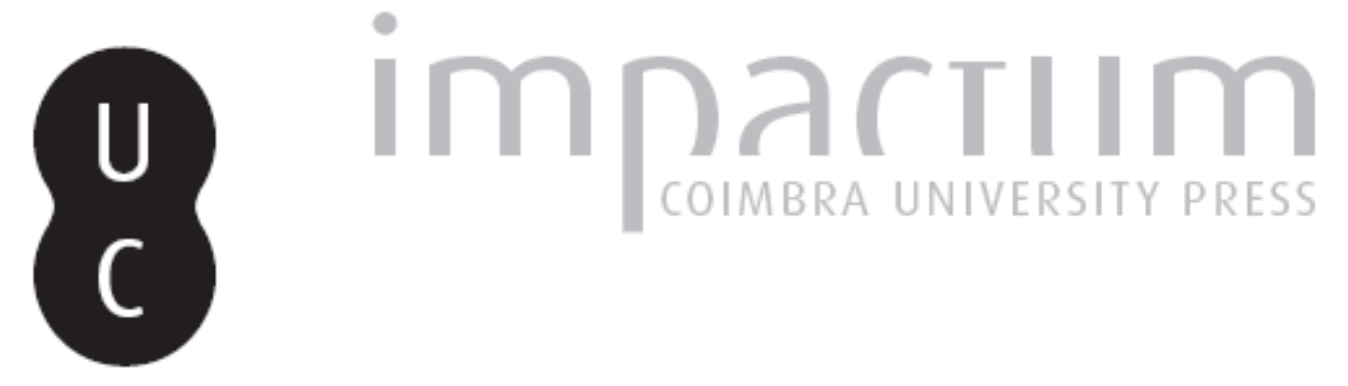

\title{
A máscara por detrás do véu do estigma: cabe o pensamento de Lévi-Strauss numa reflexão sobre a experiência da lepra?
}

\author{
Autor(es): $\quad$ Cruz, Alice \\ Publicado por: CIAS - Centro de Investigação em Antropologia e Saúde \\ URL \\ persistente: \\ URI:http://hdl.handle.net/10316.2/28844 \\ DOI: \\ DOI:http://dx.doi.org/10.14195/2182-7982_25_4 \\ Accessed : $\quad$ 26-Apr-2023 08:11:26
}

A navegação consulta e descarregamento dos títulos inseridos nas Bibliotecas Digitais UC Digitalis, UC Pombalina e UC Impactum, pressupõem a aceitação plena e sem reservas dos Termos e Condições de Uso destas Bibliotecas Digitais, disponíveis em https://digitalis.uc.pt/pt-pt/termos.

Conforme exposto nos referidos Termos e Condições de Uso, o descarregamento de títulos de acesso restrito requer uma licença válida de autorização devendo o utilizador aceder ao(s) documento(s) a partir de um endereço de IP da instituição detentora da supramencionada licença.

Ao utilizador é apenas permitido o descarregamento para uso pessoal, pelo que o emprego do(s) título(s) descarregado(s) para outro fim, designadamente comercial, carece de autorização do respetivo autor ou editor da obra.

Na medida em que todas as obras da UC Digitalis se encontram protegidas pelo Código do Direito de Autor e Direitos Conexos e demais legislação aplicável, toda a cópia, parcial ou total, deste documento, nos casos em que é legalmente admitida, deverá conter ou fazer-se acompanhar por este aviso.

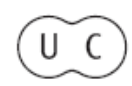




\section{Antropologia Portuguesa}

Volume $24-25 \cdot 2007-2008$

Departamento de Antropologia | Universidade de Coimbra

\section{Dossier Temático \\ CLAUDE LÉVI-STRAUSS}




\title{
A máscara por detrás do véu do estigma: cabe o pen- samento de Lévi-Strauss numa reflexão sobre a expe- riência da lepra?
}

\author{
Alice Cruz \\ Centro de Estudos Sociais \\ Universidade de Coimbra \\ alicecruz5@yahoo.com.br
}

\begin{abstract}
Resumo A partir dos testemunhos de mulheres e homens que conheceram a lepra nos seus corpos e nas suas vidas, delineou-se um eixo hermenêutico que questiona os mecanismos de naturalização do estigma cravado na lepra, bem como a sua incorporação como ontologia do doente de lepra. Em vista a um desenlace analítico do nexo simbólico entre a lepra e o estigma, buscar-se-á entender a persistência do último na orla da identidade pública das pessoas enfermas de lepra (edificada nos territórios epistemológicos e políticos da modernidade ocidental), em articulação com os universos fenomenológicos que substanciam esta enfermidade e as respostas sociais que lhe são dirigidas. Atalhando a reiteração de um olhar dicotómico que encerra a agência na antinomia entre poder e resistência, far-se-á uso da cogitação de Lévi-Strauss (1981) sobre a máscara, enquanto dispositivo que sutura uma aparente contradição entre a expressão e a intencionalidade.
\end{abstract}

Palavras-chave Lepra; estigma; silêncio; intencionalidade; máscara.

\begin{abstract}
Based on testimonies from women and men who experienced leprosy on their lives and bodies, the mechanisms that naturalize the stigma inscribed on leprosy, as well as it's incorporation as ontology for people with leprosy, are critically questioned. Regarding an analytical disentangle between leprosy and stigma, the persistence of the previous on the public identity of people with leprosy (produced on the epistemological and political territories of modernity) will be scrutinized, in articulation with the phenomenological universes that substantiate this disease, and the social responses to it. Avoiding the reiteration of a dichotomist perspective which encloses agency in the antinomy between power and resistance, use will be made of Lévi-Strauss's (1981) cogitation about the mask as a device which sutures an apparent contradiction between expression and intentionality.
\end{abstract}

Key words Leprosy; stigma; silence; intentionality; mask. 


\section{Introdução}

Em A via das máscaras, Lévi-Strauss (1981) submete as máscaras swaihwé, pertencentes aos Salish, da costa noroeste dos Estados Unidos da América, a um exame segundo os princípios da análise estrutural que advogava.

Como Fleck (1979) e Kuhn (2005) assinalaram, a produção do conhecimento é urdida sobre tramas delineadas por temporalidades específicas que, no mesmo passo em que conferem visibilidade a determinadas construções epistemológicas, obscurecem outras. Tendo isso em vista, cabe perguntar em que medida, uma vez descartado o outrora celebrado estruturalismo de Lévi-Strauss (1975), o pensamento deste autor se dota, ou não, como um instrumento útil para a reflexão contemporânea em ciências sociais?

Numa investigação etnográfica e documental conduzida na última leprosaria portuguesa, o antigo Hospital-Colónia Rovisco Pais, ${ }^{1}$ inaugurado em 1947, e cujo modelo, concordando com o paradigma transnacional de combate à lepra ${ }^{2}$ na época (Pandya, 2003), decretava o internamento compulsivo dos enfermos, emergiu um questionamento do estigma cravado nesta enfermidade, levantado pela experiência dos ex-doentes de lepra que residem no Serviço de Hansen do renomeado Centro de Medicina de Reabilitação da Região Centro - Rovisco Pais.

Partindo do eixo analítico inspirado nos seus testemunhos, desenvolverse-á uma reflexão sobre o estigma cunhado na lepra, que se apropria do desenho conceptual da máscara produzido por Lévi-Strauss, para dar conta da intencionalidade oclusa por detrás da opacidade do estigma.

Com efeito, no lastro da lepra aparenta seguir, inelutavelmente, o estigma. Indubitavelmente, o denso investimento metafórico dirigido historicamente à lepra é um processo exemplar do que Sontag (1991) descreveu como a imputação de significados morais a uma doença, transmutando-a numa metáfora com

${ }^{1}$ Esta pesquisa foi desenvolvida entre 1 de Fevereiro de 2006 e 31 de Maio de 2007, no âmbito de uma bolsa concedida pelo projecto de investigação interdisciplinar "O HospitalColónia Rovisco Pais: antropologia e história em contexto" do Departamento de Antropologia da Universidade de Coimbra, financiado pelo Instituto de Investigação Interdisciplinar da Universidade de Coimbra.

${ }^{2}$ Embora actualmente se incremente a metamorfose semântica de lepra em doença de Hansen, pretendendo-se, com isso, a diluição do estigma, neste texto far-se-á uso do termo lepra, dado que a experiência dos utentes do Serviço de Hansen se moldou num diagnóstico de lepra (na época uma doença incurável), na representação social da lepra e no imaginário metafórico em torno da lepra. 
emprego adjectival. No caso da lepra, a eficácia desse processo é atestada pela fusão semântica entre lepra e estigma, que exporta o uso do primeiro vocábulo para contextos ermos da enfermidade. O estigma figura, assim, como uma marca aviltante inscrita nos corpos das pessoas enfermas de lepra, convertendo esta doença num epítome para a exclusão social. Neste sentido, tal como na imagética medieval do doente de lepra, composta por um véu cobrindo o rosto desfigurado e por um sino notificando a sua presença, a palavra lepra insinua uma densidade simbólica espectral, velando aquilo que anuncia.

Ora, se a relação entre representação e experiência tende a delinear-se numa tensão, no caso da lepra, a mediação através do estigma dramatiza-a, produzindo um desencontro, cujo agonismo é imbuído de uma relação política e epistémica desigual que pende em favor da primeira, confluindo no silenciamento da segunda no espaço público.

Porventura, compreende-se, assim, porque a análise social do estigma enlaçado na lepra, tenda a circunscrever-se numa moldura hermenêutica que o reifica (veja-se Waxler, 1998). Expressões como "o estigma da lepra é tão antigo quanto a doença" (Jopling, 1991: 2) perduram, reforçando o vínculo dessa associação. Por conseguinte, uma análise do estigma que descure as vozes experienciais dos sujeitos, padece da transposição, apontada por Spivak (1993), dos mapas cognitivos que informam a relação de dominação para o campo epistemológico, e que conduziu a autora a concluir que o subalterno não pode falar.

Aqui, buscar-se-á, discutir os mecanismos subjacentes à produção do estigma, em articulação, como diria Hall (1996), com os universos fenomenológicos e reflexivos das mulheres e homens que conheceram os primeiros nos seus corpos e nas suas vidas. De fora, ficará o conteúdo simbólico e político do estigma nutrido no contexto histórico em causa, sendo esse indissociável do processo de medicalização ${ }^{3}$ da lepra, bem como a forte inflexão sensorial que assume a substanciação do estigma.

${ }^{3}$ Não cabendo, aqui, o exame do processo de medicalização da lepra, importa realçar a predominância da epistemologia biomédica na configuração de modelos de explicação ontológica do humano e da realidade no contexto da modernidade ocidental (Conrad, 1992: 211): “A medicalização consiste em definir um problema em termos médicos, usando uma linguagem médica, adoptando um quadro médico para compreender esse problema, ou usando uma intervenção médica para o 'tratar'. Este é um processo sociocultural que pode ou não envolver a profissão médica, levar a controlo social médico ou tratamento médico, ou ser o resultado da expansão intencional da profissão médica.”. 
O espaço analítico que se pretende delinear, pode ser pensado, assim, como um "entre-lugar", na acepção de Santiago (2000: 26) que, reportando-se à literatura latino-americana, iluminou o trânsito entre o texto do dominador e a transgressão ao texto pelo dominado, como um momento de transformação, em que, se o significante é o mesmo, o significado veicula uma outra mensagem, subvertendo, com isso, uma epistemologia que define o silêncio como negatividade e a voz como pertença de identidades puras. Este deslocamento hermenêutico apela a estratégias interpretativas que alcancem a ambiguidade do que, na esteira de Bhabha (2005a), pode ser invocado como uma agência subalterna. Ora, é precisamente, nesta perspectiva, que a reflexão de Lévi-Strauss (1981) em a Via das Máscaras, ao oferecer da máscara um entendimento que ultrapassa as suas fronteiras como artefacto cultural, edifica, como se procurará demonstrar, um conceito operativo transponível para contextos diversos e que se oferece como sendo particularmente útil para pensar a experiência do estigma. Neste sentido, este texto pretende contribuir para a resposta à pergunta atrás enunciada.

\section{A espessura histórica da persistência do estigma}

Na representação ocidental moderna da lepra, é possível detectar a persistência do espectro de uma doença bíblica, no qual se entalha a personagem do "leproso"4 medieval. Com esta imagética, compete a nosologia biomédica de doença de Hansen, que consagra um modelo etiológico em contraposição às teorias explicativas bíblicas e medievais, centrando-se numa causalidade patogénica e refutando a herança histórica que estampa ideias punitivas na lepra. Nesta competição representacional reside o âmago da produção simbólica da lepra na modernidade ocidental.

Porém, as narrativas dos utentes do Serviço de Hansen respeitantes à exclusão social, são inextrincáveis da denúncia que endereçam ao antigo Hospital-Colónia Rovisco Pais como motriz na produção do estigma.

${ }^{4}$ A palavra "leproso" transporta a violência da inscrição de uma representação social aviltante da lepra nas pessoas que dela padecem, pelo que será empregue, sempre, com o recurso a aspas, tendo como propósito exclusivo apontar essa mesma violência. 
Atente-se no testemunho de Cândida, ${ }^{5}$ internada compulsivamente aos sete anos de idade:

- Essa senhora (...) obrigaram-na a vir para cá [Hospital-Colónia Rovisco Pais] e depois ela pediu licença para ir a casa. Foi e não veio. Então mandaram a guarda lá buscá-la. (...) A assistente social mandou arrombar uma janela para a guarda entrar. Ela só teve tempo de fugir pelos milhos abaixo. (...) Desde essa altura muita gente nunca mais me falou. (...) A minha vizinha proibiu os netos de brincarem comigo.

Atente-se, também, no testemunho de Filipe:

- Iam as brigadas lá às nossas terras proibir a gente de comer a comida, ver onde é que nos sentávamos, onde é que dormíamos, essas coisas todas!

Note-se que esta denúncia não é exclusiva dos ex-doentes de lepra internados compulsivamente no antigo Hospital-Colónia Rovisco Pais (Gussow e Tracy, 1971; Maciel, 2004). As suas vozes, oferecendo a objectividade forte de um conhecimento situado (Harding, 2002), questionam, directamente, a produção do estigma no seio da medicalização da lepra, urdida nos territórios epistemológicos, políticos e sociais da modernidade ocidental, que viram erguer e derribar, entre finais do século XIX e inícios do século XX, o modelo da leprosaria moderna como profilaxia para a lepra (Mawani, 2003; White, 2003; Bernabeu e Balester, 2004).

Ora, o que lhes subjaz será menos uma avaliação das práticas terapêuticas biomédicas, e mais uma ponderação dos processos de medicalização como escultores de regimes de verdade, como diria Foucault (1977), que fabricam uma classificação social que, dada a própria arquitectura epistemológica e ideológica da ciência moderna, tende a ser naturalizada.

Com efeito, o estigma associado à lepra sendo, usualmente, atribuído à sintomatologia desta enfermidade e, muito particularmente, às sequelas incapacitantes que resultam da sua progressão no organismo humano, pende a ser naturalizado. Esta perspectiva aproxima-se da própria etimologia da palavra estigma, que indicia uma marca inexoravelmente imprimida num

${ }^{5}$ Em acordo com a vontade expressa pelos utentes do Serviço de Hansen os seus nomes serão substituídos por pseudónimos. 
objecto, indissociável, como tal, do objecto em si, descartando, logo, um terceiro termo de mediação. Ou seja, segundo esta acepção, o Outro comparece como mero espectador. Porém, dado que os processos de classificação são metaforicamente construídos num processo relacional e interpretativo (Lakoff, 1987), o estigma, enquanto categoria cognitiva que percepciona essa marca no Outro, ascende num processo de construção social.

Neste horizonte, é incontornável a ponderação de Goffman (1980). Segundo o autor, a socialidade processa-se com base em categorias socialmente produzidas que, ao serem identificadas com caracteres externos, condicionam a interacção quotidiana entre indivíduos. Relevante, é o modo como desmonta a naturalização intrínseca à construção dessas categorias, acentuando o seu carácter relacional e dinâmico, desconstruindo, assim, o estigma como ontologia. Todavia, a formulação de Goffman (1980: 22), desenvolvida no âmbito do interaccionismo simbólico, enfatiza os "contactos mistos" entre sujeitos estigmatizados e sujeitos não estigmatizados, carecendo de uma reflexão crítica que permita inquirir os processos de construção social de um estigma, e que os equacione, necessariamente, com a ordem social. Neste sentido, Goffman (1980) parece ignorar a dimensão reguladora do estigma, obscurecendo, concomitantemente, a intencionalidade política dos indivíduos sobre os quais recai. Por outro lado, ao limitar o escopo da sua análise a estratégias quotidianas de adaptação e de autopreservação (que divergiriam consoante o grau de visibilidade do estigma), o autor reitera um olhar essencialista e subentende uma incorporação do estigma pelos sujeitos.

Ora, a densidade histórica do estigma cravado na lepra suscita uma ponderação que transborde a dimensão quotidiana da socialidade, dado esta enfermidade ter sido sujeita sistematicamente a um profuso investimento metafórico que, agregando significados de origens diversas, resultou numa densidade simbólica de difícil destrinça. Ademais, embora constituindo, indesmentivelmente, uma enfermidade com corolários extremamente severos no organismo humano, a lepra tem figurado, também, como uma ideia, historicamente apropriada para fins políticos diversos. Por conseguinte, importa compreender aquilo que, na esteira da discussão de Said (2004) sobre o orientalismo, pode ser invocado como a persistência do estigma como ontologia do doente de lepra.

Esta persistência parece escorar-se na percepção social do doente de lepra como um Outro que, em sucessivos períodos históricos, incorporou o 
que Douglas (1991) sinalizou como o universo simbólico da impureza, correspondente à demarcação das fronteiras entre ordem e desordem social.

Assim, recuando às raízes da imaginação ocidental da lepra, verifica-se que no Antigo Testamento (Bíblia Sagrada, 1974), a lepra ${ }^{6}$ assoma como um castigo lançado sobre os humanos, em consequência da desobediência às regras espirituais e sociais, prescritas por Deus. Com origem numa punição divina, a lepra é respondida, socialmente, com a condenação ao ostracismo, uma vez que, tal como narra a célebre passagem do Levítico (Bíblia Sagrada, 1974), a impureza moral do "leproso" converte-o num elemento potencialmente nefasto para a comunidade, numa associação inequívoca entre o pecado e a ideia de contaminação social. Em suma, enquanto punição divina, a lepra confere materialidade ao pecado, servindo como uma denúncia que expõe na derme a degeneração da alma. Em torno, o Novo Testamento (Bíblia Sagrada, 1974) estende a ideia de uma poluição sacra, corolário da ira de Deus, à manifestação da virtude divina no próprio território da humanidade. Deste modo, a lepra, enquanto substanciação do pecado na carne, é acompanhada, também na carne, pelo seu contrário. É Jesus quem incorpora a pureza moral que permite resgatar o "leproso" da sua condição aviltante. Logo, à vocação reguladora do Antigo Testamento (Bíblia sagrada, 1974), junta-se, assim, uma dimensão soteriológica no Novo Testamento (Bíblia sagrada, 1974) que reitera, contudo, a exterioridade do "leproso".

Também os fantasmas medievais europeus, ecoando uma disseminação epidémica de lepra, descrita como um flagelo com início nos primeiros séculos da cristandade até finais do século XIII (Bérniac, 1985; Lechat, 2002) iteram o anátema bíblico e o ímpeto segregacionista. É, precisamente, aí, que a imaginação ocidental situa a proscrição mais extrema do personagem medieval do "leproso", o qual emerge como epítome da exclusão social, assolado por uma "morte em vida" (Bérniac, 1985: 137). Aliás, segundo a historiografia clássica, ${ }^{7}$ ao diagnóstico de lepra seguir-se-ia a consagração

${ }^{6}$ É necessário ter em conta que a concordância entre o conteúdo semântico da palavra lepra no contexto bíblico e no contexto biomédico actual é duvidosa. É hoje consensual que esta discrepância teve origem na tradução do termo bíblico "tzaraath" para o grego "lepra", no século II A. C., o primeiro significando castigo e impureza, descrevendo diversas dermatoses, e sendo irreduzível a uma em particular (Bérniac, 1985; Lewis, 1987; Cule, 2002; Vieira, 2003; Rawcliffe, 2006).

${ }^{7}$ Importa referir que os estudos históricos contemporâneos têm vindo a contestar a descrição da leprosaria medieval como um degredo, bem como o ostracismo absoluto atri- 
ritual de uma morte civil (Cule, 2002). Porém, também a representação medieval da lepra reitera a ideia de uma poluição sacra (Férnandez, 2004). Como descreve Rawliffe (2006), as práticas de caridade dirigidas aos doentes de lepra eram tidas como meios de salvação.

Por conseguinte, a conexão simbólica entre lepra, pecado, castigo e redenção, veio a condicionar a posição social dos enfermos em sucessivas épocas históricas. Fê-lo, contudo, postando a ambivalência no estatuto do "leproso", inspirando respostas sociais divergentes, do anátema à compaixão, não falhando ambas em sustentar a verticalidade da relação estabelecida.

Em finais do século XVI, o espectro da lepra desvaneceu-se na Europa. Para a imaginação europeia de então, a lepra transformou-se numa doença tropical (Bérniac, 1985). Durante esse período, esta doença assomou como um marcador que diferenciava o corpo do colonizador do corpo do colonizado. Todavia, em finais do século XVIII e inícios do século XIX, a lepra fez-se anunciar na Europa por via de relatos que chegavam das colónias, sendo descrita como um "perigo imperial" (Wright, 1889 in Gould, 2005: 109), decorrente da mobilidade populacional.

Foi neste contexto que despontou a leprologia moderna e que, em 1873, Gerhard Hansen, identificou o agente etiológico da lepra, o Mycobacterium leprae, introduzindo uma ruptura na história desta enfermidade, ao conferir materialidade à sua causa (Benchimol e Sá, 2003). Como resultado da acção de um microrganismo, identificado pela extensão do olhar biomédico através do microscópio (Latour, 1984), a origem da lepra foi transferida do universo da moral para o mundo da biologia e da fisiologia, consagrando a teoria do contágio como causa desta doença. A leprologia consolidou-se, então, no que Kuhn (2005: 29) designou por "ciência normal”, e a lepra converteu-se num objecto para o saber biomédico.

Não obstante, a lepra permanecia associada a um Outro, identificado, agora, com o atraso civilizacional, inscrito quer nos territórios colonizados, quer nas populações mais carenciadas das sociedades metropolitanas. No seio de um alarme público generalizado, que Gussow (1989 in Edmond, 2006: 6) denominou, sugestivamente, de "leprofobia", o crescente apoio público à instauração de medidas de contenção da lepra consagrou, em 1897, na Pri-

buído ao estatuto social do "leproso". Estas pesquisas vêm sugerindo, antes, que ambas as ideias poderão ter sido, em parte, produzidas no contexto histórico europeu do século XIX (Miller e Smith-Savage, 2006; Rawcliffe, 2006). 
meira Conferência Internacional sobre Lepra, em Berlim, a teoria do contágio e a segregação disciplinar no espaço da leprosaria moderna como profilaxia para a lepra (Pandya, 2003). Perante a carência de tratamento, a intervenção biomédica privilegiava a preservação do bem público, em detrimento da cidadania dos enfermos. A velha resposta social da segregação das pessoas padecentes de lepra retornava na moderna intervenção biopolítica.

Significativo para a ponderação da persistência do estigma, é o facto de que, embora a jurisdição biomédica sobre a lepra se tenha consolidado em ruptura com o legado bíblico e medieval, o último era transversal aos discursos médicos de então (veja-se, em Portugal, Falcão, 1900). A leprologia, enunciando uma ruptura epistemológica com o legado do Antigo Testamento (Bíblia sagrada, 1974), reclamava, em torno, a ambição soteriológica do Novo Testamento (Bíblia sagrada, 1974) para si, renovando, todavia, o estatuto subalterno do enfermo de lepra. Por outro lado, a validação do modelo explicativo biomédico, ao demandar a rejeição da representação religiosa da doença, invocando-a insistentemente, como contraponto, fez retornar ao imaginário público o espectro do "leproso", reinventando-o. Finalmente, a pedagogia profilática, aspirando combater o que considerava ser a ignorância popular do contágio, reacendia o medo social do "leproso" (veja-se, em Portugal, Carvalho, 1932).

O doente de lepra, antigo portador de uma impureza moral, transfigurou-se, assim, num vector de uma impureza patogénica, ${ }^{8}$ mas também de uma impureza social, na associação da patogenia com a insalubridade e com a pobreza. O corpo com lepra incorporava, agora, o pecado do atraso, constituindo-se num indicador civilizacional e servindo como uma "metáfora de contraste" (Ribeiro, 2004: 21).

O caso de Portugal ilustra-o, claramente, onde a lepra, enquanto ideia, traduzia a gestão da relação entre o Mesmo e o Outro no interior do espaço europeu. Até à década de 1930, Portugal carecia de um plano estratégico de combate à lepra, muito embora a sua necessidade viesse sendo denunciada pela classe médica desde a segunda metade do século XIX (Carvalho, 1932; Silva, 1967). A prevalência da lepra manchava a identidade nacional, como proferia Fernando Bissaya Barreto, o ideólogo e artífice do Hospital-Colónia Rovisco Pais (Barreto, 1940: 17):

${ }^{8}$ Como explica Douglas (1991), o conceito moderno de impureza veio a ficar inextrincável dos germes e da noção congénere de patogenia. 
"Na verdade, Portugal é o País da Europa que tem mais leprosos e o único País do Mundo Civilizado que não tem uma Leprosaria. Pode afirmarse, sem receio de contestação, que se trata de uma vergonha nacional e que a todos, Portugueses e Estrangeiros, merece a maior repulsa."

A lepra parecia recordar a modernidade europeia de um passado que almejava expurgar de si, assomando como uma doença residual de atraso civilizacional que convertia as pessoas enfermas de lepra em sujeitos sem lugar no espaço social regulado, ou por outra, em indivíduos exilados da história.

\section{A oclusão sob o véu do estigma}

Por conseguinte, o estigma aparenta configurar um instrumento classificatório em uso num processo que transborda a dimensão quotidiana da interacção social, obrigando a centrar a discussão no plano das relações de poder. Pelo que, se revela mais elucidativo ampliar a ponderação sobre os mecanismos de produção e de sustentação do estigma à moldura reflexiva que identifica o estereótipo como a paisagem simbólica onde se entretece o discurso colonial.

Bhabha (2005b) identifica a fixidez, a repetição e a ambivalência como os mecanismos subjacentes ao fabrico e ao sustento do estereótipo. Segundo o autor, o estereótipo, enquanto representação que valida a inferioridade atribuída ao Outro, cimenta-se num imaginário cristalizado, que proclama a imutabilidade tangível da adscrita negatividade. Pelo recurso à fixidez, a inferioridade do Outro é essencializada como uma condição natural. Todavia, essa mesma fixidez faz-se depender de uma repetição das negatividades apontadas, por forma a que os mesmos caracteres possam ser invocados em circunstâncias diversas, dotando-os de uma universalidade que permite, enfim, esculpir o estereótipo como verdade. Por outro lado, o estereótipo desfralda uma brecha para a ambivalência, permitindo encetar uma relação com esse Outro que, embora prenhe de negatividade, exorta ser regenerado. Nessa cisão, abre-se o espaço para a legitimação da dominação colonial, sob uma retórica salvífica em torno da pretensa superioridade moral do dominador face ao dominado (Bhabha, 2005b: 158): 
"Como forma de cisão e crença múltipla, o estereótipo requer, para que a sua significação seja bem sucedida, uma cadeia contínua e repetitiva de outros estereótipos. O processo através do qual a ‘dissimulação’ metafórica é inscrita numa falta que tem de ser ocultada confere ao estereótipo tanto a sua fixidez como a sua qualidade fantasmática - as mesmas velhas estórias da animalidade do preto, da imperscrutabilidade do coolie ou da estupidez do irlandês têm de ser contadas (compulsivamente) de forma repetida e renovada, e revelam ser, sempre que isso acontece, diferentemente gratificantes e aterradoras."

O estereótipo fornece, assim, um instrumento para a naturalização de uma hierarquia e para a concomitante legitimação da relação de dominação como uma missão soteriológica.

Por outro lado, como aponta Bhabha (2005b), o poder discursivo accionado, é um que, ao mesmo tempo que produz a diferença (conferindolhe o que pode ser descrito como uma visibilidade extrema, onde o excesso figura como estratégia central), rejeita-a e, sobretudo, vela-a. É na dobra, aparentemente paradoxal, que sutura a visibilidade com a invisibilidade, que se aloja a funcionalidade do estereótipo, bem como do estigma.

$\mathrm{Na}$ verdade, tanto o estereótipo quanto o estigma aninham-se numa percepção, socialmente instilada, de caracteres negativos, tendencialmente inscritos no corpo. Por conseguinte, ambos pendem a somatizar a diferença, produzida e classificada negativamente na dialéctica entre ordem e desordem social. A somatização das hierarquias, por um lado, faculta a sua naturalização e, por outro, insufla o cunho da negatividade, ao ponto desta se tornar numa totalidade que oculta quaisquer outros traços passíveis de serem reconhecidos. Com efeito, estereótipo e estigma são categorias classificatórias urdidas num processo metonímico (Lakoff, 1987:79):

“Os estereótipos sociais são casos de metonímia - em que uma subcategoria possui o estatuto, socialmente reconhecido, de estar para a categoria como um todo, normalmente com o propósito de suscitar um julgamento rápido sobre as pessoas."

A excessiva visibilização de um ou mais traços, gizados socialmente e inscritos num grupo de pessoas como explicação ontológica e totalizante, tem como corolário uma homogeneização das mesmas, que reverte na sua invisibilização e silenciamento. Esta opacidade transmuta-se, então, num 
factor que através de um processo iterativo reproduz a exclusão e, simultaneamente, a legitima. Tal como no espectro medieval do doente de lepra, a metaforização pública dos indivíduos tomados como objecto de estratégias sociais de exclusão, lança sobre os mesmos um véu que os homogeneíza, desindividualiza e silencia.

Por conseguinte, o estigma, transvazando uma mera categoria accionada na interacção social, no confronto entre uma "identidade social virtual" e uma "identidade social real" (Goffman, 1980: 12), deve ser pensado como um mecanismo que, mais do que ascender de uma dada posição de marginalidade social, colabora na sua construção. Por outro lado, tal como no caso do estereótipo colonial, o estigma inscrito na lepra descerra um espaço para uma ambivalência que permite encetar uma relação aparentemente mais inclusiva mas que, ao manter estável o plano da inferioridade, sustenta a exclusão. Assim, no braço biomédico que segregava, emergia o gesto soteriológico, como atesta o pensamento de Fernando Bissaya Barreto (1967:21):

"O doente de lepra - pelo mal que o aflige e que não procurou e pelo sacrifício que se lhe impõe, isolando-o da Colectividade, - é digno de respeito e atenção. Não lhes falta aqui no Rovisco Pais, nem uma nem outra... Mas daí até chegar ao ponto de se querer, como muitas vezes acontece, diminuir os rigores do acolhimento do contagiante e quebrar, assim e ali as regras da profilaxia ditadas pela ciência médica, de modo algum!"

Em suma, a persistência de imagens de poluição imputadas na lepra, desde as ideias bíblicas e medievais de uma impureza moral até à ideia moderna de uma impureza patogénica, fazendo invocar, repetitivamente, uma metonímia do "leproso" como um sujeito irremediavelmente submetido a processos de estigmatização social, cravou, inexoravelmente, o estigma na representação pública desta enfermidade, reificando-o como ontologia do doente de lepra.

A título de exemplo, atente-se na descrição de Manuel Santos Silva (1953:14), o primeiro director clínico do Hospital-Colónia Rovisco Pais:

"Coube-nos, todavia, mais do que a ninguém, tomar deles amplo e directo conhecimento, ao observar pela primeira vez e nunca mais perder de vista todos os hansenianos, repetindo-se os ensejos para apreciarmos os 
quadros dantescos da sua vida, cujas pinceladas negras encerram um mundo de martírios, ansiedades, desilusões ou esperanças."

\section{A denegação fenomenológica do estigma}

Porém, o universo do estigma não se queda na estigmatização. Com efeito, as narrativas dos utentes do Serviço de Hansen iluminam universos de sentido, oclusos pelo véu do estigma, que problematizam uma presumível incorporação da identidade que desenha sujeitos naturalmente excluídos.

Precisamente como instrumento de contestação ao estigma, foi publicada, em 1956, no Hospital-Colónia Rovisco Pais, a primeira edição da revista dos internados $\mathrm{Luz}$, na esteira da congénere The Star, publicada na leprosaria de Carville (Gaudet, 2004), ambas almejando desmontar a representação social do doente de lepra como um sujeito morto em vida (LUZ, 1956:1):

"Pela primeira vez apresentamos ao público este jornal LUZ. É um símbolo que se destina a dissipar as trevas que envolveram o flagelo «LEPRA» que, desde os tempos bíblicos até há bem pouco tempo, era considerado como incurável. Actualmente, pode afirmar-se, graças aos modernos processos de tratamento com as Sulfonas, que esse mal é perfeitamente curável, no maior número dos casos. Persistem ainda muitos erros e preconceitos sobre essa doença e suas vítimas. Para os eliminar de vez nos resolvemos a editar este modesto jornal."

Ainda que retidos numa liminaridade que deslizava para a marginalidade, dado não pressupor um deslindar da opacidade (Turner, 1974), os indivíduos, compulsivamente internados no Hospital-Colónia Rovisco Pais, diligenciaram, activamente, a construção do seu modo de vida, tanto no interior dos muros segregacionistas, quanto no seu exterior. Neste sentido, o silêncio do sujeito subalterno emanou de uma relação de poder desigual que, muito embora tenha velado publicamente a sua intencionalidade, não a anulou. A questão que aflora é, portanto, da viabilidade em se conceber a voz e a agência além da dialéctica clássica entre poder e resistência. 
Um primeiro aspecto a ter em conta, prende-se com o facto dos exdoentes identificarem, também eles, o estigma com as sequelas dermatológicas e motoras da lepra. Veja-se o que disse a este propósito João:

- O meu irmão também teve a doença, mas vai a todo o lado e está com toda a gente, porque não tem... não tem os problemas que eu tenho! (...) anda normal, ao passo que eu... Agora, eu era convidado para ir a algum lado, e ia assim, encostado a uma bengala, não!

O contágio, embora constituindo o motor da segregação social e do exílio disciplinar, configura um elemento passível de ser encoberto. Porém, a invisibilidade do contágio e a visibilidade das sequelas dermatológicas e motoras imbricam-se uma na outra, as segundas representando uma memória do primeiro que instiga a persistência do medo social, não obstante a cura clínica. Acerca disto contou Duarte:

- Queria telefonar para aqui para dizer que se não houvesse carro, chamava um táxi, porque me queria ir embora [do Hospital Distrital da Figueira da Foz]. Pedi o telefone a uma enfermeira. Ela disse-me que tinha de esperar porque estava um senhor a usá-lo. Percebi logo que era conversa. Levantei-me, não tinha roupa, estava de pijama e descalço, fui para o corredor e comecei a berrar alto:

“-Que raio de médicos são estes? Onde é que esta gente aprendeu? Os grandes cientistas do mundo não conseguem manter um bicho da lepra vivo num tubo de ensaio à temperatura do corpo, com o caldo de cultura certo, e ele morre, e fica aqui agarrado ao raio do telefone?"

- Mas acha que não o queriam deixar telefonar por causa disso?

- E não deixaram mesmo! Para eu não pegar no telefone.

Indubitavelmente, como os próprios ex-doentes afirmam, o estigma vinculado à lepra, condiciona a sua interacção social no espaço público. O que não denota, forçosamente, a incorporação do estigma, tanto no que pode ser invocado como o sentimento de si, quanto na sua reflexividade. Ou seja, a relação entre identidade e identificação não é, necessariamente, analógica, como expressou Duarte: 
- O que é que se sente numa situação dessas em que se percebe que as pessoas têm medo?

- É... é revoltante, pronto! O que é que se há-de fazer? Isso é uma daquelas coisas que me choca imenso.

- E isso afecta a auto-imagem, a maneira como a pessoa se vê a si mesma?

- A auto-imagem acho que não. Acho que isso não me afecta. Só que simplesmente gera-me revolta.

É, assim, frequente, em contextos de exposição pública, reivindicarem uma distinção entre o seu corpo desenhado pela doença e o self ${ }^{9}$. Duarte, a propósito do olhar veiculado pelos meios de comunicação social, assinalava:

- Eles vêm para aqui e só querem fotografar os mais aleijadinhos, não querem saber do ser intrínseco.

Um segundo aspecto, que emerge na ampliação fenomenológica ao campo da "intersecção" de experiências, ou da "intersubjectividade" (Merleau-Ponty, 1999: 18), respeita à prática constante de uma vigilância do Outro, que determina o encetamento ou a denegação da comunicação. Como explicam os ex-doentes, no momento em conhecem alguém, começam por apreciar os indícios que permitem antever a resposta do outro. Assim, se as pessoas enfermas de lepra foram objecto de uma rejeição social que ascendia na representação do doente de lepra como vector de uma impureza patogénica, as mesmas respondem com a rejeição da impureza moral daqueles que os discriminam. Veja-se o seguinte episódio narrado por Eurico:

- Enquanto trabalhava lá fora, houve um indivíduo que era filho de um doente que esteve aqui e disse que o pai dele tinha estado aqui e que eu também tinha estado aqui. De todas as pessoas que souberam disso, só uma é que fugia de mim. Ele era carpinteiro e nunca pegava numa coisa que eu the desse, se pegava era depois, passado um bocado, no fim dos bichos estarem mortos é que ele pegava [ri-se]. Quer dizer, aí nessa obra andei lá 24 meses e as pessoas ficaram todas a saber que eu estive aqui.

${ }^{9}$ Dada a dificuldade da tradução do termo para português, mantém-se a expressão em inglês, que alude ao que pode ser invocado como o sentimento de si. 
- E como foi a reacção delas?

- Não reagiram nem mal, nem bem. Era como uma coisa que não se tivesse passado. Não ligaram nada. Se comiam comigo, continuaram a comer, não ligaram nada, e a beber. E então quando acabou essa obra fui para outra obra e fui-me encontrar com aquele indivíduo que teve medo de mim e eu jogava o totobola mais um moço e ainda fizemos uns pontos e o homenzinho tinha lá uma sociedade, mas como nós fazíamos mais pontos que eles, ele queria jogar connosco. E eu disse-lhe: “- Eu não jogo consigo, você diz que tem medo de mim."

Também neste sentido, os ex-doentes, perante a estigmatização social, respondem com uma desqualificação inversa do Outro. Pondo a claro a simultaneidade de situações de reconhecimento da igualdade entre indivíduos enfermos de lepra (ou que o foram no passado) e indivíduos não enfermos de lepra, com outras que, ao contrário, reflectem uma desqualificação e discriminação dos primeiros pelos segundos, os ex-doentes sugerem que a estigmatização social se faz depender de uma escolha que cabe aos segundos tomar, enquanto sujeitos dotados, também eles, de reflexividade e de agencialidade. Ouça-se o que disse Duarte:

- Há pessoas que aceitam. Já está curado, está tudo bem. Quanto ao resto, depende das pessoas! Quem tem medo... tem medo! É um sentimento humano! [ri-se] Há quem não tenha medo! Têm medo de uma coisa que já não existe! Se um tipo já não tem nada... Está tudo negativo, mas no entanto há pessoas que continuam a ter medo!

Nessas situações, tendem a contestar, activamente, as respostas sociais de exclusão, seja no curso da interacção quotidiana, seja através do protesto público, como, no passado, quando um grupo de internados, onde se incluía Duarte, destinou ao Vaticano uma reivindicação que exigia a actualização das referências à lepra nos Evangelhos, em acordo com os dados científicos disponíveis, nomeadamente no que concerne ao contágio e vias de transmissão.

Ou seja, os ex-doentes recusam que um encontro entre duas pessoas se transforme num "encontro entre uma pessoa e um objecto" (Hughes, 2002: 71). Neste sentido, a sua reflexão aventa uma sugestão particularmente importante. Ainda que identifiquem o estigma com as sequelas físicas pro- 
vocadas pela lepra, os ex-doentes remetem para o Outro a responsabilidade pela estigmatização, fazendo-a depender menos de quem é olhado e mais de quem olha. Ao ressaltarem a heterogeneidade das respostas sociais que lhes são dirigidas, num eixo entre a reciprocidade e a rejeição, imputam o ónus da exclusão ao Outro. Curiosamente, a sua reflexão aproxima-se da proposta do modelo social dos estudos sobre deficiência, desenvolvido nas sociedades do Norte, a partir de meados da década de 1970 (Barnes, Oliver e Barton, 2002). Esse deslocamento transparece a denegação de uma identificação fenomenológica com o estigma como ontologia do doente de lepra.

Contudo, essa denegação tem uma expressão prenhe de ambivalência, que exige um entendimento que não se deixe tolher por uma hermenêutica essencialista.

Ao longo das suas vidas, os ex-doentes fizeram um uso estratégico do segredo. Não apenas procuraram ocultar a doença na sequência do diagnóstico, como o fizeram, principalmente, após a alta hospitalar. No regresso ao espaço público, esse silêncio permitiu-lhes camuflar um aspecto das suas vidas que problematizaria o estabelecimento de novas redes de sociabilidade, como respondia Eurico:

- Então, quando esteve a trabalhar na Figueira da Foz não disse que tinha estado aqui?

- Não.

- Era melhor não dizer?

- Era melhor não dizer.

No mesmo sentido, declarava Amália:

- Na altura notava-se a doença?

- Não. Notava-se umas manchas. Tinha uma mancha na cara.

- Quando é que se começou a notar mais? Quando veio para cá?

- Não, foi lá, quando eu fui ao médico. Aquela mancha na cara não havia maneira de sair. E depois a cara começou a ficar mais grossa, a inchar, eu nem via. Ele receitou-me uma pomada rosada e eu esfregava naquele sítio e a cara ficava rosa. As pessoas diziam-me: "- Tens a cara inchada, é dos dentes?”. Eu dizia: “- Pois.”.

- Para as pessoas não saberem?

- Pois. Mas ia à missa, ia a todo o lado. 
Assim, o silêncio emergiu, na experiência dos ex-doentes, como um mecanismo que, mais do que resultar de uma incorporação do estigma, faculta uma circulação, desagrilhoada do seu peso, entre diversos espaços sociais.

Ao encobrimento socialmente produzido pelo véu do estigma, estas pessoas responderam com outro modo de encobrimento activo, que pode ser pensado com apelo à ideia de máscara. ${ }^{10}$ Para isso, invoco a cogitação de Lévi-Strauss (1981).

\section{A máscara como outro lado do véu}

Como foi dito atrás, Lévi-Strauss (1981) aplicando a análise estrutural às máscaras swaihwé, dos Salish, transpõe o exame da funcionalidade ou da forma, para buscar o seu conteúdo epistemológico na relação com as máscaras de contextos vizinhos, nomeadamente as dzonokwas e as xwéxwé dos Kwakiutl. Da sua comparação, o autor retira a seguinte ilação: “Quando, de um grupo para outro, a forma plástica se conserva, a função semântica inverte-se. Pelo contrário, quando se mantém a função semântica, é a função plástica que se inverte." (Lévi-Strauss, 1981:79; itálico do autor).

Ou seja, para Lévi-Strauss (1981:124), a máscara anuncia uma tensão entre processos de dissimulação e processos de manifestação, cuja inteligibilidade, não se encerrando na sua idiossincracia, repousa numa comunicação relacional que a máscara integra e protagoniza:

“(...) uma máscara não existe em si; a máscara pressupõe, sempre presentes a seu lado, outras máscaras, reais ou possíveis, que poderiam ter sido escolhidas para a substituírem (...) uma máscara não é, principalmente, aquilo que representa mas aquilo que transforma, isto é: que escolhe não representar. Como um mito, uma máscara nega tanto quanto afirma; não é feita somente daquilo que diz ou julga dizer, mas daquilo que exclui."

Neste sentido, Lévi-Strauss (1981) forja um conceito que permite alcançar o outro lado dessa dobra que sutura a visibilidade com a invisibilidade, atrás identificada como mecanismo que subjaz à funcionalidade

${ }^{10}$ Num sentido diverso ao que será, aqui, discutido, mas que, em igual modo, oferece uma reflexão sobre a invisibilidade como estratégia agencial, ver Frois (2003/2004). 
do estigma. A máscara, enquanto dispositivo relacional, cuja aptidão para revelar, repousa na sua capacidade para ocultar, permite dar conta de identidades que, em relação agonística com uma dada representação social, accionam uma performatividade que não é, necessariamente, análoga à intencionalidade que a instiga.

No caso dos ex-doentes de lepra, o uso do outro lado do véu do estigma como máscara, verifica-se na ocultação do seu historial clínico que, embora sendo facilitada pela ausência de sinais da doença na superfície do corpo, não é inviabilizada pela sua manifestação. Disso patente, é o facto de que, muito embora os ex-doentes ostentem sequelas da enfermidade, não se identifiquem como tal no espaço público, tal como afirmam Amália e Belinda:

- E quando vão lá fora dizem que tiveram a doença?

Amália - Ninguém diz nada.

Belinda - Ninguém diz.

Ou seja, a capacidade para ocultar o historial da lepra não se esgota na ausência de sinais corporais, contrariando a distinção analítica de Goffman (1980).

Ao ocultarem o historial da lepra, os ex-doentes invertem a produção da invisibilidade, obliterando, precisamente, o mesmo traço que, sendo excessivamente realçado pelo estigma, se convertera numa totalidade que suprimia os restantes aspectos das suas individualidades e das suas identidades sociais.

Neste sentido, o segredo enquanto máscara, é menos uma estratégia performativa e adaptativa de disfarce, e mais um mecanismo que faculta a manifestação dos caracteres pessoais e sociais encobertos pela compulsão totalizante e homogeneizante do estigma.

Em torno, o uso do próprio véu como máscara, insinua-se na apropriação do mesmo dispositivo que atalhou a sua cidadania, o Hospital-Colónia Rovisco Pais, como um instrumento emancipatório no presente, ao reivindicarem, enquanto ex-doentes de lepra compulsivamente internados no passado, o direito a receber cuidados médicos, sociais e económicos continuados.

$\mathrm{Na}$ verdade, a sua permanência no Serviço de Hansen decorre menos de uma carência de redes sociais externas, e mais da vantagem de um acesso a serviços médicos e apoios financeiros de todo inviáveis no exterior. Neste sentido, a revelação do historial da lepra (exactamente a mesma identidade 
que se repudia noutros contextos sociais, como se viu atrás) sugere que a assunção do véu do estigma, fazendo uso da mesma representação que legitima a exclusão, não resulta da incorporação do estigma, mas configura, antes, uma estratégia emancipatória. Veja-se o caso de Eurico:

- Eu fui-me embora em 1972. Já lhe contei de me quererem dar alta forçada... compulsivamente... e de eu não querer. Eu disse-lhes: “- Eu tenho aqui um perfurante e enquanto isto não sarar eu não vou nem para casa, nem para Tábua, nem para lado nenhum, tenho que sarar aquilo. Eu tenho um filho e uma filha, se for lá para fora, tenho eu que ir trabalhar para os sustentar a eles, que eles são pequeninos. Por isso não vou, não saio nem morto." Aqui tinha o subsídio daqui e também tinha o abono de família de lá. E não gastava e ainda levava para casa.

Em conversa com João e Duarte, o primeiro, que visita frequentemente a mulher e os filhos mas que insiste em permanecer no Serviço de Hansen, respondeu assim à seguinte interrogação:

- Porque é que não fica em casa com a sua família?

João - Se eu ficasse lá, a minha pensão não chegava para os medicamentos e tratamentos.

Duarte - Acha que ainda tínhamos de pagar depois de termos aguentado aqui no Rovisco Pais 50 e tal anos, a sofrer aqui, ainda tínhamos que pagar?

Fanon (1967:10) esclarece, exemplarmente, o aparente paradoxo do uso estratégico dos mecanismos da opressão por parte dos sujeitos oprimidos, quando afirma, numa crítica profunda à colonialidade do poder e do saber, ${ }^{11}$ que: "Para o homem negro só existe um destino. E esse é branco". Subsequentemente, Fanon (1967) desmonta o exercício da camuflagem identitária como uma resposta às relações de dominação, iluminando a intencionalidade do sujeito oprimido no acto de assunção de uma identidade que lhe é imposta pelo opressor.

Ora, aquilo que está implícito no uso do véu do estigma como máscara, é essa arte da invisibilidade, mecanismo de sobrevivência social possuído e

\footnotetext{
${ }^{11}$ Sobre a colonialidade do poder e do saber ver Quijano (2000) e Mignolo (2003).
} 
protagonizado pelo sujeito subalterno, de que fala Bhabha (2005a: 92): “A negação da posição da mulher migrante - sua invisibilidade social e política - é usada por ela em sua arte secreta de vingança, a mímica."

A ambiguidade do accionamento díspar de estratégias de camuflagem ou de declaração de uma identidade pública desenhada pela lepra, indica que a relação com uma determinada inscrição identitária varia consoante os contextos e os fins almejados, emergindo como uma formulação dinâmica e intersubjectiva, que esboroa concepções essencialistas de agência e de identidade. Staples (2003:307) verificou igual maleabilidade no contexto da experiência da lepra no Sul da Índia: “O contraste nítido entre situações nas quais as deformidades são disfarçadas e outras em que são propositadamente enfatizadas, mostra como as relações dos indivíduos com os seus corpos mudam radicalmente de acordo com o contexto."

Em suma, o sujeito subalterno, no curso da sujeição a processos políticos e epistémicos de invisibilização social, desenvolve uma relação estratégica com a própria condição de invisibilidade que lhe é imposta, dela fazendo um uso intencional e selectivo. Por conseguinte, a violência do silêncio a que se vê votado, é transmutada pelo mesmo em agência, num uso hábil do segredo, deixando o silêncio de ser um produto da dominação para se tornar numa estratégia de transgressão.

\section{Conclusão}

Procurou-se, aqui, escrutinar a persistência do estigma enlaçado na lepra. Para isso, impôs-se uma atenção aos processos históricos de uma “discriminação estrutural" (Yang et al., 2007:1527).

Verificou-se que o estigma, contrariamente à alegação biomédica que o descreve como resíduo de uma cosmologia que assimila a lepra ao pecado, transpôs as fronteiras simbólicas que apartam a ciência da religião, para se aninhar na representação ocidental moderna desta enfermidade. A impureza moral inscrita na lepra, transfigurou-se, no curso do século XIX, numa impureza patogénica e social que a modernidade anelava expulsar de si, desenhando a lepra como uma doença residual de atraso civilizacional que convertia os enfermos em sujeitos exilados da história. Não obstante, e, ao contrário do que defendem Gussow e Tracy (1971), o estigma não constitui uma mera invenção da regulação biopolítica. Antes, a sua persistência resultou de uma "superioridade posicional flexível" (Said, 2004:8) 
por parte das elites religiosas, médicas e políticas, que reiterava a exterioridade na representação, forjando diferentes classificações dos enfermos que, deslizando num eixo entre a compulsão segregacionista e o ímpeto soteriológico, iteravam uma metonímia do doente de lepra como sujeito naturalmente excluído, produzindo, paradoxalmente, o eclipse do mesmo objecto que ressaltavam. Neste sentido, a lepra assoma como uma "doença de fronteira" (Edmond, 2006: 10) que incorporou, historicamente, diferentes formulações de desordem social.

Apesar de reconhecerem a presença perene do estigma na orla da sua identidade pública, os ex-doentes de lepra do Serviço de Hansen do antigo Hospital-Colónia Rovisco Pais, denegam uma identificação fenomenológica com aquele. Por um lado, distinguindo o estigma do processo social de estigmatização, imputando o ónus do segundo ao Outro. Por outro lado, convertendo o silêncio e a ocultação disciplinar em estratégias transgressoras de sobrevivência social.

Foi, precisamente, o conceito de máscara, proposto por Lévi-Strauss (1981), que permitiu dar conta da variabilidade e da ambivalência dos processos de ocultação e de revelação do historial clínico e existencial da lepra, no contexto de uma performatividade social dúctil, imbricada em redes de intersubjectividade e de relacionalidade política.

Assim, em resposta à pergunta inicialmente elaborada, o deslocamento da reflexão de Lévi-Strauss (1981) para uma análise do estigma cunhado na lepra, permitiu distinguir as estratégias de representação que omitem a voz do sujeito subalterno de um efectivo mutismo do último, ${ }^{12}$ iluminando esse movimento intersticial de transgressão que transmuta o véu da exclusão numa máscara de emancipação.

\section{Bibliografia}

Barnes, C.; Oliver, M.; Barton, L. 2002. Introduction. In: Barnes, C.; Oliver, M.; Barton, L. (eds.). Disability studies today. Cambridge, Polity Press: 1- 17. Barreto, F. B. 1940. Relatório da Junta Geral do Distrito de Coimbra. A Saúde, X: 16-18.

${ }^{12}$ Distinção que Spivak (1999) veio a conceder na revisão da sua resposta negativa à interrogação que lançara sobre a possibilidade de um discurso subalterno. 
Barreto, F. B. 1967. O serviço social na luta contra a lepra. Rovisco Pais: Revista Portuguesa da Doença de Hansen, 6 (2): 17-32.

Benchimol, J. L.; Romero S. M. 2003. Adolpho Lutz e as controvérsias sobre a transmissão da lepra por mosquitos. História, ciências, saúde - Manguinhos, 10 (1): 49-93.

Bernabeu, J.; Balester, T. 2004. Disease as a metaphorical resource: the Fontilles philantropic initiative in the fight against leprosy, 1901-1932. Social History of Medicine, 17 (3): 409-421.

Bérniac, F. 1985. O medo da lepra. In: Le Goff, J. (ed.). As doenças têm história. Lisboa, Terramar: 127-145.

Bhabba, H. K. 2005a. O local da cultura. Belo Horizonte, Editora UFMG.

Bhabba, H. K. 2005b. A questão outra: estereótipo, discriminação e o discurso do colonialismo. In: Sanches, M. R. (org.). Deslocalizar a "Europa” : antropologia, arte, literatura e história na pós-colonialidade. Lisboa, Edições Cotovia: 143-166.

Bíblia sagrada. 1974. Lisboa, Sociedades Bíblicas Unidas.

Carvalho, A. S. 1932. História da lepra em Portugal. Porto, Oficinas Gráficas da Sociedade de Papelaria, L. ${ }^{\text {da }}$.

Conrad, P. 1992. Medicalization and social control. Annual Review of Sociology. 18: 209-32.

Cule, J. 2002. The stigma of leprosy: its historical origins and consequences with particular reference to the laws of wales. In: Roberts, C. A.; Lewis M. E.; Manchester, K. (eds.). The past and present of leprosy: archaeological, historical, paleopathological and clinical approaches: proceedings of the international congress on the evolution and paleoepidemiology of the infectious diseases 3 (ICEPID). Oxford, Bar: 149-23.

Douglas, M. 1991. Pureza e perigo: ensaio sobre as noções de poluição e tabu. Lisboa, Edições 70.

Edmond, R. 2006. Leprosy and empire: a medical and cultural history. Cambridge, Cambridge University Press.

Falcão, Z. 1900. A lepra em Portugal. Lisboa, Academia Real das Ciências de Lisboa.

Fanon, F.1967. Black skins, white masks. New York, Grove Press.

Férnandez, E. M. 2004. Fantasmas de la sociedad medieval: enfermedad, peste, muerte. Valladolid, Universidad de Valladolid.

Fleck, L. 1979. Genesis and development of a scientific fact. Chicago, The University of Chicago Press. 
Foucault, M. 1977. Discipline and punish: the birth of the prison. London, Penguin Books.

Frois, C. 2003/2004. (A) Negociação da identidade nos grupos de auto-ajuda: o caso das Famílias Anónimas. Antropologia Portuguesa, 20/21: 37-57.

Gaudet, M. 2004. Carville: remembering leprosy in America. Jackson, University Press of Mississippi.

Goffman, E. 1980. Estigma: notas sobre a manipulação da identidade deteriorada. Rio de Janeiro, Zahar Editores.

Gould, T. 2005. A disease apart: leprosy in the modern world. New York, St. Martin's Press.

Gussow, Z.; Tracy, G. S. 1971. The use of archival materials in the analysis and interpretation of field data: a case study in the institutionalization of the myth of leprosy as "leper”. American Anthropologist, 73 (3): 695-709.

Hall, S. 1996. Introduction: Who needs “identity”? In: Hall, S.; Gay, P. D. (eds.). Questions of cultural identity. London, Sage: 1- 17.

Harding. S. 2002. Rethinking standpoint: theory epistemology: what is "strong objectivity"? In: Harding, S. (ed.). The feminist standpoint reader: intellectual and political controversies. New York, Routledge: 127-140.

Hughes, B. 2002. Disability and the body. In: Barnes, C.; Oliver, M.; Barton, L. (eds.). Disability studies today. Cambridge, Polity Press: 58-76.

Jopling, W. H. 1991. Leprosy stigma. Leprosy Review, 62: 1-12.

Kuhn, T. S. 2005. A estrutura das revoluções científicas. São Paulo, Perspectiva.

Lakoff, G. 1987. Women, fire and dangerous things: what categories reveal about the mind. Chicago and London, The University of Chicago Press.

Latour, B. 1984. Les microbes: guerre et paix suivi de irreductions. Paris, Editions A. M. Métailié.

Lechat, M. E. L. 2002. The paleoepidemiology of leprosy: an overview. In: Roberts, C. A.; Lewis M. E.; Manchester, K. (eds.). The past and present of leprosy: archaeological, historical, paleopathological and clinical approaches: proceedings of the international congress on the evolution and paleoepidemiology of the infectious diseases 3 (ICEPID). Oxford, Bar: 157-162.

Lévi-Strauss, C. 1975. Antropologia estrutural. Rio de Janeiro, Tempo Brasileiro

Lévi-Strauss, C. 1981. A via das máscaras. Lisboa, Editorial Presença.

Lewis, G. 1987. A lesson from Leviticus: leprosy. Man, 22 (4): 593-612.

LUZ, 1956. 8 de Dezembro: 1.

Maciel, L. R. 2004. “A solução de um mal que é um flagelo": Notas históricas sobre a hanseníase no Brasil do século XX. In: Nascimento, D. R.; Carvalho, 
D. M. (orgs.). Uma história brasileira das doenças. Brasília, Paralelo 15: 109-125.

Mawani, R. 2003. "The island of the unclean": race, colonialism and "chinese leprosy" in British Columbia, 1891-1924. Law, Social Justice \& Global Development [Acedido em 01-11-2007]. http://elj.warwick.ac.uk/global/03-1/ mawani.html

Merleau-Ponty, M. 1999. Fenomenologia da percepção. São Paulo, Martins Fontes.

Mignolo, W. 2003. Os esplendores e as misérias da ciência: colonialidade, geopolítica do conhecimento e pluri-versalidade epistémica. In: Santos, B. S. (ed.). Conhecimento prudente para uma vida decente: um discurso sobre as ciências revisitado. Porto, Afrontamento: 667-709.

Miller; T. S.; Smith-Savage, R. 2006. Medieval leprosy reconsidered. International Social Science Review, 81 (1,2): 16-28.

Monteiro, Y. N. 2003. Profilaxia e exclusão: o isolamento compulsório dos hansenianos em São Paulo. História, ciências, saúde - Manguinhos, 10 (1): 95-121.

Pandya, S. S. 2003. The First International Leprosy Conference, Berlin, 1897: the politics of segregation. História, Ciências, Saúde - Manguinhos, 10 (1): 161-77.

Quijano, A. 2000. Colonialidad del poder, eurocentrismo y América Latina. In: Lander, E. (ed.). La colonialidade del saber: eurocentrismo y ciencias sociales. Perspectivas latinoamericanas. Buenos Aires, CLACSO Y UNESCO: 201-230.

Rawcliffe, C. 2006. Leprosy in medieval England. Suffolk, The Boydell Press.

Ribeiro, M. C. 2004. Uma história de regressos: império, guerra colonial e póscolonialismo. Porto, Afrontamento.

Said, E. 2004. Orientalismo. Lisboa, Cotovia.

Santiago, S. 2000. Uma literatura nos trópicos: ensaios sobre dependência cultural. Rio de Janeiro, Rocco.

Silva, M. S. 1953. Relatório das gerências desde o início das actividades (27 de Outubro de 1947) a Dezembro de 1952 / Hospital-Colónia Rovisco Pais. Coimbra, Coimbra Editora, Limitada.

Silva, M. S. 1967. A luta anti-lepra em Portugal. Rovisco Pais: Revista Portuguesa da Doença de Hansen, 6 (22) 8-36.

Sontag, S. 1991. Illness as metaphor and Aids and its metaphors. London, Penguin Books.

Spivak, G. C. 1993. Can the subaltern speak? In: Williams, P.; Chrisman, L. (eds.). Colonial discourse and post-colonial theory. Harlow, Longman: 66-111. 
Spivak, G. C. 1999. A critique of postcolonial reason: toward a history of the vanishing present. Cambridge, Harvard University Press.

Staples, J. 2003. Disguise, revelation and copyright: disassembling the south Indian leper. Journal of the Royal Anthropological Institute, 9: 295-315.

Turner, V. 1974. Dramas, fields and metaphors: symbolic action in human society. Ithaca, London.

Vieira, R. A. 2003. A lepra: bosquejo histórico. Notícias Médicas, 2759: 17-21.

Waxler, N. E. 1998. Learning to be a leper: a case study in the social construction of illness. In: Brown, P. J. (org.). Understanding and applying medical anthropology. California, Mayfield Publishing Company: 147-157.

White, C. 2003. Carville e Curupaiti: experiências de isolamento e comunidade. História, Ciências, Saúde - Manguinhos, 10 (1): 123-41.

Yang, L. H.; Kleinman, A.; Link, B. G.; Phelan, J. C.: Lee, S.; Good, B. 2007. Culture and stigma: adding moral experience to stigma theory. Social science \& medicine, 64: 1524-1535.

Artigo recebido a 23 de Julho de 2008 e aceite a 1 de Setembro de 2008. 